\title{
Valve failure in an injection port
}

\author{
H. Adler $\cdot$ R. Cunningham $\cdot$ R. Parimkayala
}

Received: 29 June 2009/Accepted: 5 October 2010/Published online: 21 October 2010

(C) Royal Academy of Medicine in Ireland 2010

\section{Dear Sir,}

We wish to report an interesting incident involving a Venflon ${ }^{\circledR}$ 16-gauge ported intravenous cannula.

Prior to an abdomino-perineal resection on a 65-year-old male, a Venflon ${ }^{\circledR} 16$-gauge ported cannula was inserted into the left cephalic vein at the wrist.

During the operation, a pool of blood (about $50-100 \mathrm{ml}$ ) was noticed on the floor under the left-hand armboard. The armboard was draped at the time so neither the arm nor the cannula was visible.

Investigation revealed that the source of the bleeding was the injection port on the Venflon cannula. At the time, the infusion was switched off and the cap on the port was open, but even on closing the cap the leak continued. We were surprised that the venous pressure was such as to allow for such blood loss from the patient's left cephalic vein superficial to the distal radio-ulnar joint. Our initial reaction was to suspect accidental arterial cannulation or cannulation of an unidentified arterio-venous fistula, but neither of these was the cause.

Subsequent to the operation, the cannula was removed and tested. Leakage at the injection port was confirmed using a saline-filled syringe (see Fig. 1). On looking into the injection port the small grey valve was partially out of position. We conclude that a defective one-way valve was responsible for the cannula malfunction.

H. Adler $(\bowtie) \cdot$ R. Cunningham

University College Dublin, Dublin, Ireland

e-mail: hugh.adler@ucdconnect.ie

\section{R. Parimkayala}

Wexford General Hospital, Wexford, Ireland
This incident gives us two issues to ponder. Firstly, as Venflon ${ }^{\circledR}$ cannulae have been in use uneventfully for many years, and their quality of manufacture is excellent, this incident demonstrates that even with familiar and welltrusted equipment, we must never lower our guard to the possibility of faulty manufacture.

Secondly, on this occasion the blood loss was a small percentage of blood volume, as the patient was a $90-\mathrm{kg}$ adult, and there were no sequelae. However, had the patient been an infant or neonate, a leaking injection port could have been a more serious matter.

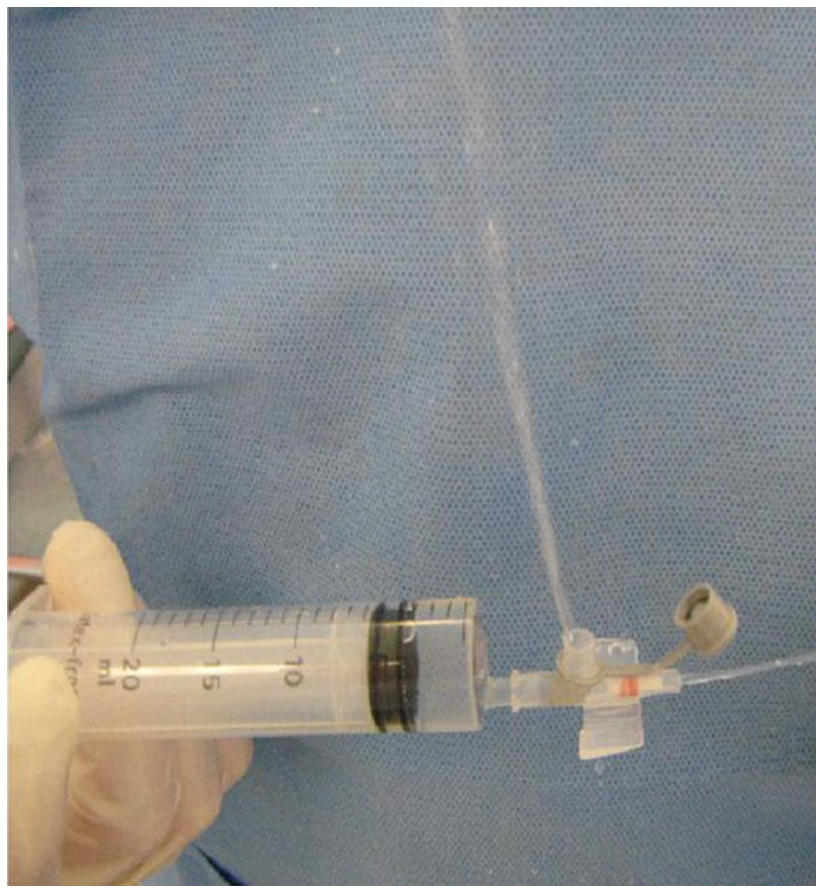

Fig. 1 Demonstration of the malfunctioning valve in the cannula injection port 